\title{
EL ESTILO ARQUEOLÓGICO COMO HUELLA COLONIAL: REFERENTES DE LA ALFARERÍA PREHISTÓRICA TARDÍA EN CHILE CENTRAL
}

\author{
ARCHAEOLOGICAL STYLE AS COLONIAL TRACE: REFERENCES \\ IN THE LATE PREHISTORIC POTTERY FROM CENTRAL CHILE
}

Nicole FuenzalidA ${ }^{A}$

El artículo discute perspectivas del estilo alfarero en el marco de la expansión inka en Chile central (1400-1536 DC) y reflexiona sobre los "lentes" que operan en clave colonial-civilizatoria. Se considera el estilo y la disgregación de sus "referentes culturales" como instancia dinámica, relacionada con la agencia artesanalartística y los contextos sociopolíticos. Se postulan categorías estilísticas con referentes locales, cuzqueños y diaguitas, y se plantea que, si bien las comunidades incorporaron nuevos estándares tecnológicos y pautas de diseño, hay principios de exclusión respecto de sus modos de vida tradicionales como parte de la práctica política estatal y los esfuerzos por persistir y resignificar el nuevo orden.

Palabras clave: Estilo, Referentes culturales, Alfarería, Colonialidad, Inka, Chile central.

This paper discusses perspectives on the pottery style in the context of the inka expansion in central Chile (1400-1536 AD) and reflects on the "lenses" that operate in a colonial-civilizatory way. The style and the disintegration of its "cultural references" are regarded as dynamic, in relation to the artisan-artistic agency and the socio-political contexts. Stylistic categories with local, Cuzco, and Diaguita references are proposed. It is suggested that, although the communities incorporated new technological standards and design patterns, there are principles of exclusion regarding their traditional lifestyles as part of the political practice of the state and of the efforts to persist and to re-signify the new order.

Keywords: Style, Cultural References, Pottery, Coloniality, Inka, Central Chile.

\section{INTRODUCCIÓN}

La problemática del estilo ha sido fundamental en el desarrollo del pensamiento arqueológico, no solo porque permitió la reflexión renovada sobre qué se entiende por tipologías de la cultura material, conformando hasta la actualidad un campo delimitado de estudio del arte rupestre (Domingo \& Fiore 2014), sino porque se fue constituyendo en una herramienta esencial para la explicación cultural, casi un imperativo analítico a nivel disciplinar (Carr \& Neitzel 1995). Esta puede ser la razón de que, en la literatura arqueológica, se entienda por "estilo" distintos aspectos. Así, tanto los "modos de hacer" (Dietler \& Herbich 1998) como los "modos de hacer técnicos" (Lechtman 1977, Stark 1999), las expresiones de "normas e identidad" (Sacket 1990, Wiessner 1990), de "ideologías" (Shanks \& Tilley 1992), de "relaciones entre personas" (Wobst 1977) o de "agencia" (Hegmon \& Kulow 2005), por nombrar algunos, manifiestan la complejidad y multidimensionalidad que implica.

En este trabajo se discute sobre las nociones de estilo utilizadas para entender los límites sociales en época de dominación inka. ${ }^{1}$ Desde una óptica fundada en conceptos como "colonialidad del poder" (Quijano 1999), se propone situar la instancia teórica del "estilo arqueológico" en tanto "huella colonial". De este modo,

\footnotetext{
A Nicole Fuenzalida, CECLA, Universidad de Chile, Santiago, Chile. Orcid: 0000-0003-4096-4384. E-mail: nicole.fuenzalida. bahamondes@gmail.com
} 


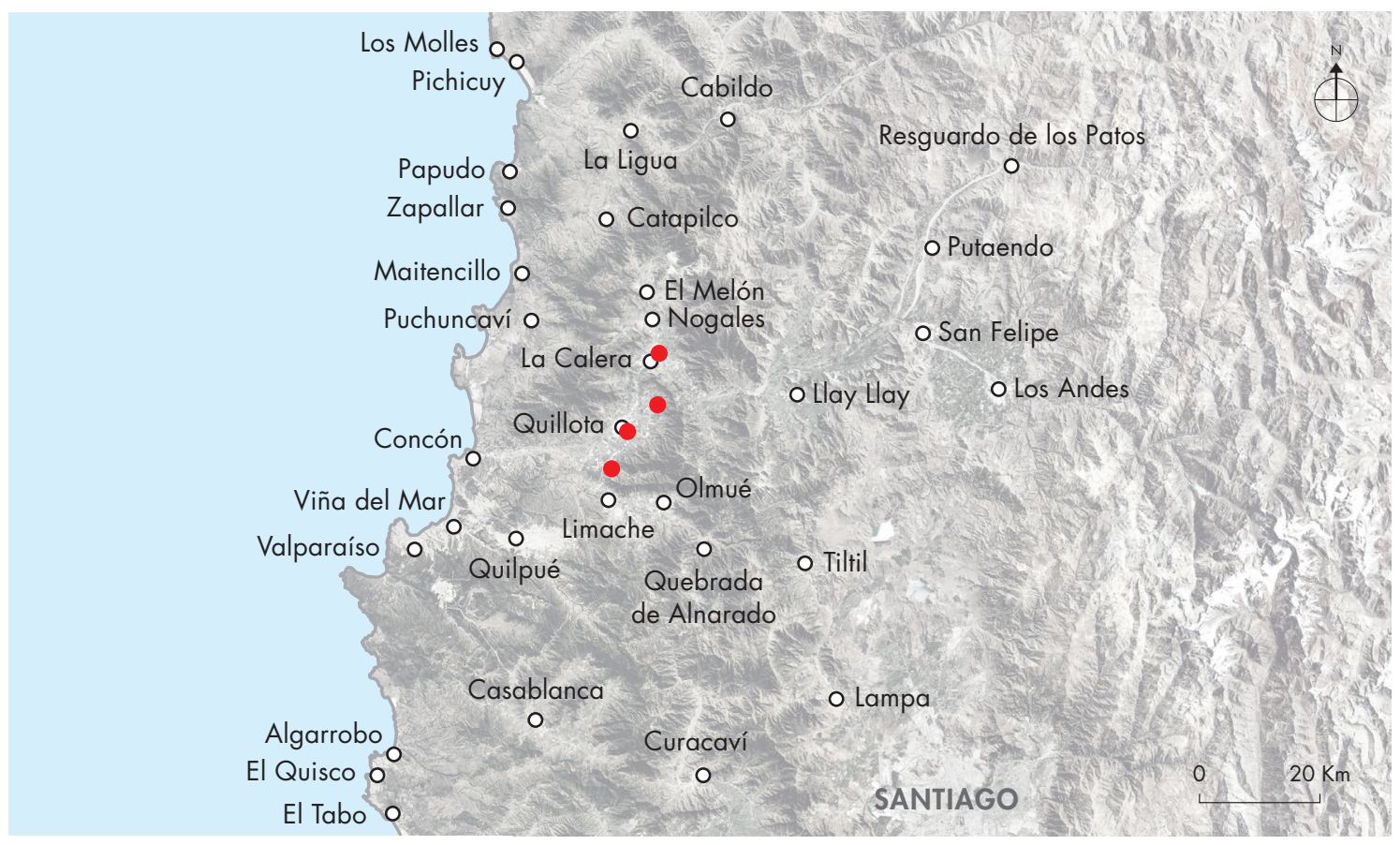

Figura 1. Área de estudio en la cuenca media-inferior del río Aconcagua. En ícono rojo los sitios arqueológicos denominados de norte a sur: Maltería, Carolina, Estadio Quillota y Fundo Esmeralda. Figure 1. Study area in the middle-inferior basin of the Aconcagua river. In red, the archaeological sites named from north to south: Maltería, Estadio Quillota, and Fundo Esmeralda.

buscamos explicitar posiciones y "lentes" (Bourdieu 2012) relacionados con determinados fundamentos coloniales de la arqueología chilena. Usaremos la problematización crítica de los estudios culturales latinoamericanos para dar cuenta de las posibilidades de elaboración teórica que se abren. ${ }^{2}$ Ello apunta no solo a tematizar la necesidad de tener en cuenta la matriz experiencial de la colonialidad -como dicen Gnecco y Langebaek (2006): "controlar la tiranía"-, sino también bosquejar los rasgos dinámicos, heterogéneos, multifacéticos y contextuales del estilo, a partir de la noción de "referentes culturales" aplicada a la alfarería que circuló en espacios funerarios del curso medio-inferior del valle del Aconcagua, ${ }^{3}$ en tiempos prehispánicos tardíos (1400-1536 DC) (fig. 1).

\section{LA COLONIALIDAD COMO MATRIZ EXPERIENCIAL}

"Lo colonial" se aborda desde una definición amplia, es decir, más que una etapa histórica, que podríamos mencionar como "colonialismo", por colonialidad entendemos una experiencia que atraviesa toda nuestra historia, "una huella" - parafraseando a Quijano (1999)- anclada en la idea de poder, saber, orden y nación (Ansaldi \& Giordano 2012, Brendecke 2012). Es una matriz profundamente civilizatoria, racista, etnocéntrica, antropocéntrica y patriarcal, concebida desde la universalización de la modernidad occidental (Quijano 1999, Dussel 2004). Esta matriz alude a un complejo patrón de dominación y resistencias, que deviene en la construcción histórica de "raza", de "género", de "clase" y de categorías como "indio", mediante procesos de violencia brutal y homogeneización de la alteridad, desarrollados desde el siglo XVI en adelante (Lugones 2011).

Una primera cuestión que se plantea entonces es ¿cómo pensar los mundos prehistóricos considerando que la huella de la colonialidad nos antecede en las elaboraciones del pasado? La respuesta debiese comenzar con una conciencia que implique asumir la colonialidad, criticar, desaprender/aprender constantemente. Es decir, indisciplinarnos de los supuestos que se reproducen en nuestros marcos disciplinares (Haber 2011). Igualmente, es necesario sostener una polivocalidad y una pluralidad epistémica que señale la autosuficiencia intelectual de una alteridad que se 
clausura en sí misma, o que no depende de diferencias, semejanzas o jerarquías (Adorno 1988, Salomon 2001, Dussel 2004). Junto a ello, se deben cuestionar las temporalidades progresivas, considerar el giro ontológico hacia los objetos y valorizar el rol del mundo no humano (Olsen 2007). Un paso podría ser tener en cuenta el pasado colonial, para desarrollar los lineamientos de un proyecto descolonizador (Verdesio 2012).

Concordamos con Martínez et al. (2014) respecto de las dudas sobre la dicotomía oralidad-escritura como la principal diferencia que existiría entre los medios de expresión de las sociedades andinas y los de las europeas colonizadoras. Coincidimos también en la necesidad de avanzar hacia la tematización de las manifestaciones visuales y de la materialidad.

En segundo lugar, podemos reconocer que la existencia de un patrón dominante en estas relaciones no equivale a ignorar los elementos conflictivos y alternativos que conviven (Quijano 1999), pues si bien la dominación forzaba a la imitación, igualmente es posible identificar espacios de apropiación, manipulación y subversión (Adorno 1984, Echeverría 2011). Se puede mencionar, por ejemplo, cómo en la discursividad de Guamán Poma de Ayala se interiorizó la eficacia de la imagen como prueba, utilizando tanto la escritura alfabética como los preceptos historiográficos humanistas y lineales para posicionar un código pictórico, semiótico y espacial diferente (Adorno 1984). A su vez, en el caso de los artistas fabricantes de queros del siglo XVI, estos mantienen valores, estructuras narrativas y técnicas tradicionales andinas, a las que integran formas pictóricas españolas (Cummins 2004, Martínez et al. 2014).

Siguiendo a Gruzinski (1994), debiésemos ser capaces de imaginar la existencia de "caleidoscopios" preeuropeos o etnicidades múltiples conviviendo. Particularmente ilustrativo es el caleidoscopio de Santiago colonial, descrito por Valenzuela (2010), con la convergencia de inmigrantes de Cochabamba, Guayaquil, Lima, Puerto Viejo (Ecuador), entre otros. Inmigrantes que utilizaron para los registros jurídicos de la época la denominación genérica de "cuzco", orientada a reivindicar el Tawantinsuyu como espacio de ennoblecimiento simbólico-político y de memoria colectiva andina. En contraste con la idea de la "soledad histórica" de Octavio Paz como signo de debilidad bélica, se destaca un rasgo señalado por Echeverría (2011) en el análisis de la figura de Malintzin, sobre la apertura y capacidad de integración de la "alteridad", que formaría parte de las lógicas socioculturales indígenas y, en general, de las americanas (Boccara 1999, Viveiros de Castro 2017).

\section{EL ESTILO ALFARERO EN LA PREHISTORIA TARDÍA DEL ACONCAGUA}

El período prehispánico tardío en Chile central fue por mucho tiempo descrito por historiadores. En una primera etapa, desde la historiografía moderna se otorgó un rol civilizatorio a la conquista inkaica (Barros Arana 2000 [1884]). Su percepción connotó que las comunidades locales eran "simples salvajes", y posicionó este espacio como "frontera" (Oyarzún 1910). En una segunda etapa, fue primando una idea de dominio militar y económico indirecto, mediatizado por mitimaes diaguitas (Silva 1978). Pocos trabajos arqueológicos se hicieron cargo de esta problemática, hasta que se consideraron las estrategias de dominio simbólico empleadas por el Inka, registradas en santuarios de altura, complejos arquitectónicos, cementerios, alfarería, metalurgia, arte rupestre, entre otros (Uribe 1999-2000; González 2000; Sánchez 2001-2002, 2004; Pavlovic et al. 2012; Troncoso et al. 2012; Letelier 2017; Pavlovic et al. 2019).

No obstante, en este proceso de investigación regional creciente existen espacios que han permanecido marginales. Es el caso de la cuenca media-inferior del Aconcagua, donde las labores arqueológicas se remitieron al estudio de localidades (Gajardo Tobar \& Silva 1970, Ávalos \& Saunier 2011). Dicha marginación investigativa no se condice con la relevancia que este espacio adquirió para la historia colonial temprana, como centro de producción alimentaria y mano de obra indígena para la explotación de las minas del Marga Marga (Contreras 2004). En este marco, una de las expresiones materiales más importantes ha sido la alfarería, no solo por su ubicuidad en los registros de la zona, sino por el rol que tuvo su circulación en espacios festivos y funerarios, destacando su agencia en la negociación política entre el Inka y las comunidades (Fuenzalida 2014). En general, la variabilidad alfarera del período es interpretada mediante clasificaciones estilísticas, que incluyen nociones más amplias relativas a cómo se desarrollan identidades sociales, interacciones y tecnologías, entre otras. Con objeto de ilustrar los "lentes" que operan, optamos por agrupar, en perspectivas arbitrarias, aquellos trabajos que estarían funcionando como "canon" o corpus consagrado para la arqueología tardía de Chile central. 


\section{Perspectiva normativa}

El primer lente plantea que la presencia de una alfarería con atributos diaguitas correspondería a grupos provenientes del Norte Chico, quienes habrían producido dicha manufactura movilizados por el Tawantinsuyu (Rodríguez et al. 1993, Sánchez et al. 2004). Se trata de una concepción básicamente "normativa", porque instaura una relación directa entre estilo alfarero arqueológico y una identidad étnica; es decir, la presencia de un "estilo" identificaría a una "cultura" o "grupo étnico". Esta aproximación no aclara si defiende la idea de una producción foránea de dicha alfarería, tampoco desarrolla otra clase de mecanismos que habrían permitido la circulación. Por otra parte, se desprende que la práctica de movilización incluye relaciones de implantación, invasión o conquista de mitimaes diaguitas sobre las comunidades locales.

\section{Perspectiva de la interacción y similitud}

El segundo lente sostiene que la tradición alfarera local adoptaría formas y diseños provenientes del Cuzco adaptándolos a la realidad local, conformando así copias burdas o imitaciones del original. Dicha perspectiva supone una explicación de la interacción social relacionada con procesos de "aculturación rápida" sobre las "poblaciones locales" (Sánchez 2001-2002, Correa et al. 2007-2008). Desde este punto de vista, la proposición principal asume implícitamente que la similitud estilística entre los grupos es proporcional a la intensidad de la interacción entre estos. No obstante, desde estudios etnoarqueológicos se ha establecido que una intensa interacción no implica necesariamente una mayor cercanía estilística, porque la cultura material de estos grupos puede contribuir a mantener las fronteras sociales (Hodder 1982). Además, se encuentra subyacente una mirada culturalista del estilo, que suponía el entendimiento de una relación de dominio unilateral del Inka sobre las poblaciones locales.

\section{Perspectiva de la influencia}

El tercer lente es propio de los análisis realizados sobre la cerámica Diaguita del Norte Chico, que se importa a Chile central (Cantarutti \& Mera 2002) y a espacios asociados, como el centro oeste argentino (Prieto-Olavarría \& Tobar 2017). Al respecto, se había asumido tradicionalmente que el efecto de la expansión inka en el Norte Chico se materializaba en la aparición de "híbridos locales", compuestos por elementos cuzqueños y diaguitas. Sin embargo, estudios más detallados han percibido un conjunto cerámico más variable que integra el universo representacional local con aquel de orígenes diversos. Es así como desde el análisis del diseño decorativo (González 1995) se describe la existencia de "influencias" de las culturas Inka-Paya y Saxamar en el conjunto diaguita de la zona. En González (2013) se destaca la continuidad de la representación cerámica con patrones decorativos diaguitas preinkaicos, la incorporación y modificación de diseños de origen cuzqueño (simétricamente más simples y con principios de cuatripartición), y la existencia de nuevas síntesis de ambas tradiciones conocidas como Mixtos Inka-Diaguita.

También se establece que fueron los artesanos diaguitas quienes adoptaron y adaptaron formas, decoración y técnicas de manufactura desde el bagaje inkaico (González 2013: 54). Por su parte, Cantarutti (2002) pondera las similitudes y diferencias entre los estilos cerámicos del Noroeste Argentino y Diaguita, distinguiendo, entre otras categorías, una alfarería Diaguita Mixta con influencia Yavi, y una Diaguita Mixta con influencia Yavi y Cuzqueña. Con un enfoque centrado en los contextos de uso y producción, plantea que la "alfarería de estilo Inka" evocaría la figura estatal, y que aquella empleada por las sociedades locales se habría comportado como soporte propio de comunicación. Por ejemplo, en la "alfarería Inka Provincial de producción local" se reconocerían las "imitaciones" de los tipos definidos por Rowe para el Inka Cuzqueño (Rowe (1944). En ambos planteamientos existen esfuerzos por problematizar la variabilidad alfarera del período, entregando nuevas herramientas analíticas. Mas, el uso del término "influencia" y de otras acepciones, como "imitación”, denota interpretaciones lineales del proceso, de sus interacciones asociadas y de los efectos que una cultura podría producir sobre otra. Estos términos restan mérito a la intención bien fundamentada de proporcionar mayor espacio a la agencia local.

\section{Perspectiva de la "mezcla"}

El cuarto lente utiliza nociones como "mixturas", "mezclas", "combinaciones" y "sincretismos", para conceptualizar los estilos "Inka Provincial" e "Inka Local", ubicados principalmente en espacios trasandinos (Páez \& Giovannetti 2008), aunque también presentes en el área (Dávila et al. 
2018). Desde la crítica latinoamericana, se han hecho patentes las tensiones que conllevan conceptos como "mestizaje", "mezclas y mixturas", e incluso "hibridez" (Gruzinski 1991). Esto porque actuarían en determinados contextos como una ideología política que enmascara drásticamente -bajo mantos de convivencia armónicossituaciones muy conflictivas, como esclavitud, migración forzada, colonización, explotación económica, violencia generalizada, choque cultural, entre otros (Cornejo Polar 1997, Nitschack 2016). A su vez, la expresión "sincretismo" genera una idea confusa en cuanto a la "contaminación que connota" y a la consecuente reducción de la complejidad del universo social, que permanece subsumida en la ambigüedad de definiciones dualistas (Gruzinski 1991). Así, el uso indiscriminado de estos conceptos puede conducir al vacío de sus significantes históricos (Stolcke 2007, Rappaport 2015), de sus cargas ideológicas y, en definitiva, de sus violencias.

\section{EL ESTILO ARQUEOLÓGICO COMO INSTANCIA CULTURAL DINÁMICA}

En las perspectivas expuestas hay una operación de etiquetado que sometió la variabilidad de los contextos arqueológicos (espacios funerarios, habitacionales, ceremoniales, entre otros) a la distinción de estilos homogéneos, descritos a partir de los años 50. Desde ahí, el estilo alfarero, como instancia, resulta poco problematizado. Asimismo, y en parte por conformar el canon arqueológico, estos estilos se asumen usualmente como entidades con existencia social, incurriendo sistemáticamente en esencialismos y reificaciones, particularmente respecto de las representaciones de los diseños decorativos alfareros. ${ }^{4}$ Por otro lado, se tiene generalmente la idea del estilo como un elemento diagnóstico en la distinción de "etnicidades"; sin embargo, no se ofrece mayor explicación acerca de por qué este señalaría una identidad cultural dada.

Desde estas perspectivas, los "lentes" sirvieron para la explicación de la dominación e interacción social en claves coloniales-civilizatorias. Es decir, a través de un enfoque que concibe esta interacción como relaciones unilaterales de poder, como "aculturación" y "dominio indirecto", que supusieron siempre a las comunidades en un rol pasivo, invisibilizado y menospreciado. En atención a ello, nos preguntamos ¿ ¿cuánto de continuidad y vigencia guarda aún la retórica modernista de Barros
Arana, que calificó a estas comunidades de "tribus salvajes", "simples" y "bárbaras", en oposición al carácter civilizador que supuso la conquista inka en esta zona? (Colmenares 2006, Contreras 2010).

Nuestra propuesta se dirige a tematizar los patrones de variación estilística como reacciones al contexto de interacción, producción y agencia artesanal en el que se desarrollan (Friedrich 1970, Gosselain 2000, Hegmon \& Kulow 2005). Estos contextos y sus materialidades se entienden como procesos de elaboración permanente, con cualidades performativas mutuamente implicadas y altamente dinámicas (Kopythoff 1991, Gell 1994, Ingold 2012), lo que nos conduce a rechazar nociones como aculturación, contaminación, influencia, entre otras (Fuenzalida 2014). De esta manera, se considera que los estilos son instancias culturales heterogéneas, es decir, altamente permeables a la adopción de nuevas clases de diseño, formatos, técnicas y tecnologías, según los contextos culturales, sociales y políticos, y las posibilidades de agencia artesanal (Fuenzalida 2014).

Con la primigenia aproximación al estilo desarrollada por Sacket (1990), se postuló la "variación isocréstica" o el espectro de alternativas igualmente equivalentes de opciones viables para alcanzar el final previsto en la fabricación artefactual. Dicho modelo descansa en el supuesto principal de que es poco probable que cada elección hecha por una sociedad se realice también en otra no relacionada, dado que el potencial de opciones es tan grande y estas, a su vez, están determinadas por sus propias tradiciones tecnológicas. Esas elecciones particulares en un tiempo y espacio determinados se convierten en elementos históricamente diagnósticos $y$, por tanto, en indicadores de etnicidad. A pesar de las limitantes que se visualizan en la concepción de etnicidad, el aporte del autor radica en presentar el estilo como una cuestión de elecciones que no solo residiría en los atributos decorativos, sino también en cualquier variación formal que ostente un artefacto.

Aunque parezca evidente, hay que destacar que la alfarería, como cualquier otra materialidad, es fabricada por actores sociales con un conocimiento según el cual deciden para qué, por qué, cómo y cuánto producir. Se trata de opciones que no han sido determinadas exclusivamente por causas medioambientales, sino que son, ante todo, arbitrarias, condicionadas por el contexto en el cual los agentes aprenden dichas prácticas (Dietler \& Herbich 1998, Sanhueza 2004). Dicho de otro modo, en todo proceso de producción de manufactura alfarera, el 
artesano se apropia de los referentes de su entorno -ya sean ideas, técnicas o materiales procedentes de la interacción con otros artesanos, como también la memoria preexistente y su particular tradición tecnológica-, para otorgar un nuevo contenido cuya inteligibilidad se expresa en los esquemas que constituyen el artefacto y en su dominio, donde se valida ante la comunidad (Gallardo et al. 2012).

En San José de Michoacán, México, ante la decoración de las cerámicas producidas por otros talleres artesanales de su comunidad, una alfarera expresó "yo no puedo ver algo sin copiarlo" (Friedrich 1970: 337). Este caso ilustra la dimensión dialogante que tiene el estilo, el cual contempla el desarrollo de procesos de aprendizaje y cognición que se reproducen tradicionalmente al interior de las comunidades, pero que dependen también de la interacción social intercomunitaria. Así, cada estilo está construido en relación con otros y no habría ninguno que no se entienda desde esa perspectiva. Lo que fundamentaría el estilo no sería su contenido cerrado u homogéneo, sino sus posibilidades de apertura a otros distintos. En el origen de todo estilo existe una tensión social entre estándares, convenciones y normas de quienes aportan tanto a la conservación como a la innovación (Hegmon \& Kulow 2005).

Se plantea, entonces, utilizar el concepto general de referente cultural para distinguir atributos visuales (composiciones, motivos decorativos o unidades mínimas de diseño), morfológicos (formas o atributos específicos) y tecnológicos (por ejemplo, la preparación de pastas), que sean susceptibles de identificar en un determinado estilo, y que se relacionen con otros estilos exponentes de tales atributos (Fuenzalida 2014: 24).

Quisiéramos destacar con ello las posibilidades de intertextualidad (Martínez et al. 2014) y, en definitiva, la dimensión dialogante que tiene el estilo como producción cultural, así como la función activa que ostentan los artesanos y sus comunidades en este proceso creativo. Estos referentes pueden haber sido incorporados intencionalmente o no, ya sea en la forma de alusión, apropiación, recreación, entre otras acciones no excluyentes, y cumpliendo distintas funciones de acuerdo con la situación sociohistórica.

\section{REFERENTES EN EL ESTILO ALFARERO TARDÍO DEL ACONCAGUA}

Para ejemplificar lo dicho anteriormente, se presenta el análisis de 18 piezas museográficas completas, procedentes de diversos contextos funerarios del área (tabla 1). ${ }^{5}$ La clasificación estilística se basó en Calderari y Williams (1991), pero se agregó mayor definición en los límites de cada categoría. De este modo, el énfasis se encuentra en la disgregación de los estilos en "referentes" decorativos y morfológicos, considerando los aportes de la producción local. En esta última, diferenciamos la cerámica que emerge en el Período Tardío de aquella que presenta un claro referente preinkaico (Fuenzalida 2014). ${ }^{6}$ Cabe acotar que en la propuesta metodológica y clasificatoria de Cantarutti (2002) también se plantean acercamientos al concepto de "referente", lo que permite establecer relaciones.

Los aríbalos integrados en la categoría "Inka Mixta de referentes locales, cuzqueños y diaguitas" concuerdan con los parámetros formales usuales descritos para estos en las provincias. Así, se alejan del referente cuzqueño (Meyers 1975), pues no se aprecian asas en suspensión dispuestas bajo el borde, modelados bajo el cuello, como tampoco bases pequeñas convexas (o ápodas) (fig. 2a). Tampoco guardan una proporcionalidad simétrica entre cuerpo y cuello que las acerque al tipo cuzqueño, cuya proporción es de 60/40 y 70/30 (Fernández Baca 1971). Pero sí incorporan diseños decorativos cuzqueños, entre los que destaca un ejemplar (fig. 2c) cuyos atributos específicos escapan de la forma estándar regional (fig. 2b), ya que posee un cuerpo esférico de gran tamaño y albergaría una capacidad volumétrica máxima de 35 lt. La decoración comprende una banda anular en el cuello junto a un motivo en arco entre las asas y, pese a que se encuentra altamente afectado por la erosión, se distinguen otros adornos como líneas oblicuas paralelas, además de una hilera de cruces y zigzags (fig. $2 \mathrm{~d}$ ). Estos modelos decorativos están presentes tanto en el Norte Chico como en Chile central (Sanhueza 2001, Cantarutti 2002).

La botella (fig. 3) resultó ser un ejemplar singular, pues combina, como referente morfológico, estilos inkas poco frecuentes (Meyers 1975). Si bien esta botella se acerca a algunas de cuello estrecho (Matos 1999: 143), no posee el modelado antropomorfo característico dispuesto en el tercio superior del cuello. Además, tiene elementos formales que remiten a la estructura general 
Tabla 1. Síntesis de las características de los estilos alfareros expuestos. Table 1. Summary of the characteristics of the pottery styles presented.

\begin{tabular}{|c|c|c|c|c|c|}
\hline $\begin{array}{l}\text { CATEGORIAAS } \\
\text { ESTILISTICAS }\end{array}$ & $\begin{array}{l}\text { MORFOLOGÍAS } \\
\text { GENERALES }\end{array}$ & $\begin{array}{l}\text { CANTIDAD } \\
\text { TOTAL DE PIEZAS }\end{array}$ & $\begin{array}{l}\text { MOTIVOS DECORATIVOS } \\
\text { PRINCIPALES }\end{array}$ & $\begin{array}{l}\text { REFERENTES } \\
\text { MORFOLÓGICOS }\end{array}$ & $\begin{array}{l}\text { REFERENTES } \\
\text { DECORATIVOS }\end{array}$ \\
\hline \multirow{3}{*}{ Inka Mixta } & Aríbalos & 1 & En arco & $\begin{array}{l}\text { Cuzqueños y } \\
\text { locales }\end{array}$ & $\begin{array}{l}\text { Cuzqueños, } \\
\text { Diaguita, Inka } \\
\text { Mixta de Chile } \\
\text { central }\end{array}$ \\
\hline & $\begin{array}{l}\text { Botella de cuello } \\
\text { estrecho }\end{array}$ & 1 & Reticulado oblicuo & $\begin{array}{l}\text { Cuzqueños, Inka } \\
\text { Mixto del Noroeste } \\
\text { Argentino }\end{array}$ & Cuzco Polícromo \\
\hline & $\begin{array}{l}\text { Platos planos con } \\
\text { asa ojal o maciza }\end{array}$ & 2 & $\begin{array}{l}\text { Zigzag, en arco, volutas, } \\
\text { reticulado oblicuo }\end{array}$ & $\begin{array}{l}\text { Cuzqueños y } \\
\text { locales }\end{array}$ & $\begin{array}{l}\text { Cuzqueños, } \\
\text { Diaguita, Inka } \\
\text { Mixta de Chile } \\
\text { central, Saxamar }\end{array}$ \\
\hline $\begin{array}{l}\text { Alfarería de } \\
\text { Fase Inka }\end{array}$ & $\begin{array}{l}\text { Ollas de perfil } \\
\text { compuesto e } \\
\text { inflectado }\end{array}$ & 6 & $\begin{array}{l}\text { Chevrón, bidentados, } \\
\text { triángulo con pestañas, } \\
\text { patrón cadenas, reticulado } \\
\text { oblicuo, entre otros }\end{array}$ & Locales, Aconcagua & $\begin{array}{l}\text { Aconcagua y } \\
\text { Diaguita }\end{array}$ \\
\hline \multirow{2}{*}{$\begin{array}{l}\text { Aconcagua } \\
\text { Patrón Local }\end{array}$} & $\begin{array}{l}\text { Ollas de perfil } \\
\text { inflectado y cuerpo } \\
\text { esférico, elipsoide } \\
\text { u ovoide }\end{array}$ & 3 & Acordelados & Locales, Aconcagua & Aconcagua \\
\hline & $\begin{array}{l}\text { Escudillas de } \\
\text { cuerpo esférico, } \\
\text { elipsoide y ovoide }\end{array}$ & 5 & Cruciforme & Aconcagua & $\begin{array}{l}\text { Aconcagua, del } \\
\text { Maipo Mapocho }\end{array}$ \\
\hline
\end{tabular}

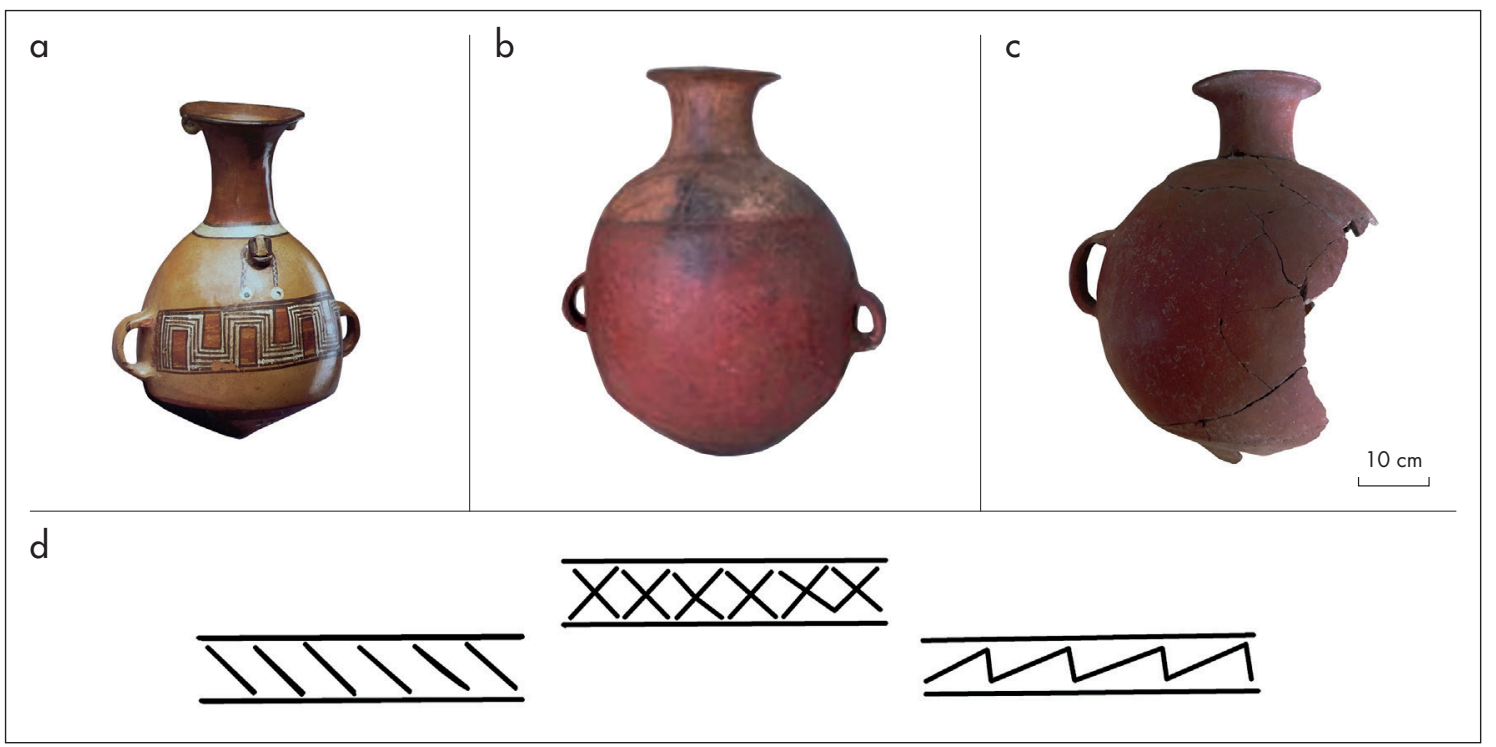

Figura 2. Aríbalo: a) Cuzqueño (modificado de Matos 1999: 119); b) Inka Chile central (modificado de Stehberg \& Sotomayor 2012: 91 , fig. 2); c) Inka Mixto en estudio. (Fotografía de la autora); d) patrones decorativos. (Dibujo de F. Gili). Figure 2. Aryballos: a) Cuzqueño (adapted from Matos 1999: 119); b) central Chile Inka (adapted from Stehberg \& Sotomayor 2012: 91, fig. 2); c) Mixed Inka under study. (Photograph by the author); d) decorative patterns. (Drawing by F. Gili). 


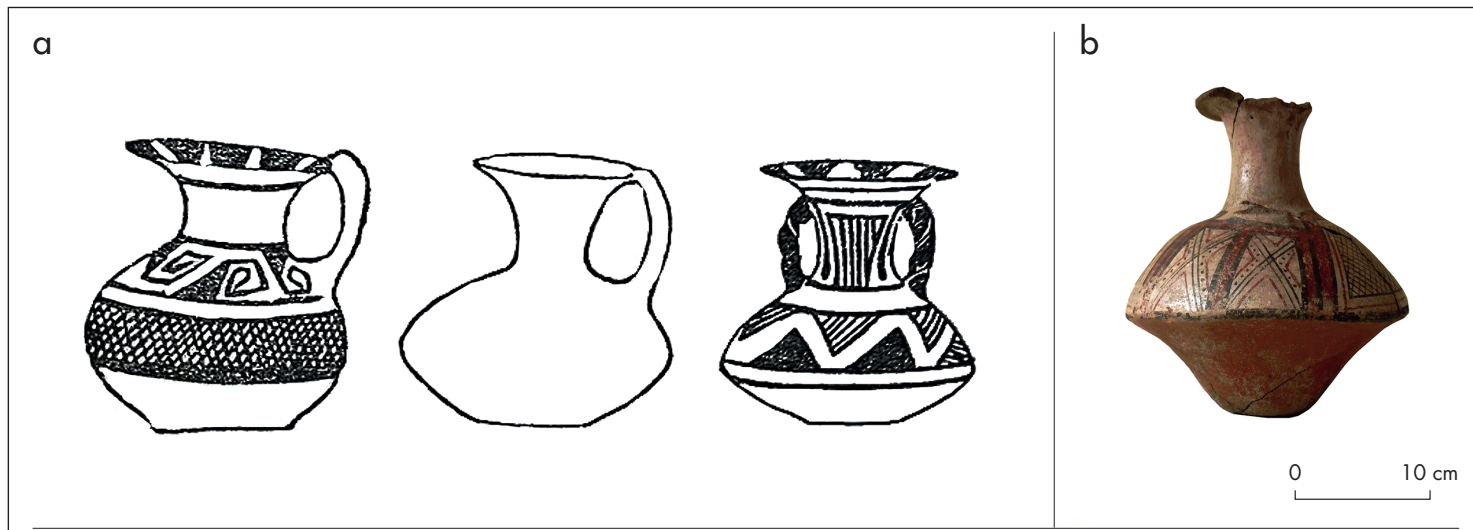

C
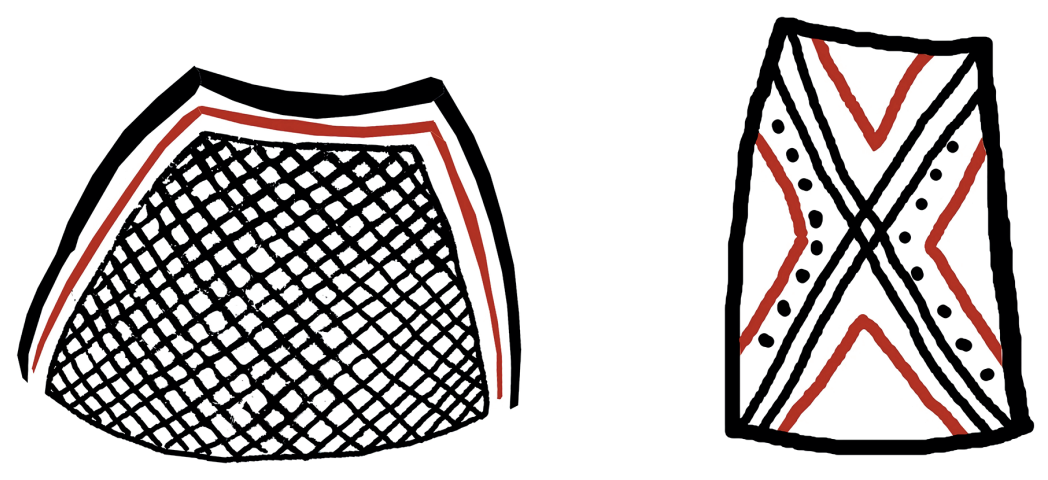

Figura 3. Botella: a) ejemplares del Noroeste Argentino (modificado de Ambrosetti 1907: 389, fig. 203 n 1971, 1844, 2130); b) pieza Inka Mixta en estudio. (Fotografía de la autora); c) patrones decorativos. (Dibujos de F. Gili). Figure 3. a) pieces from the Argentine Northwest (adapted from Ambrosetti 1907: 389, fig. 203 n 1971, 1844, 2130); b) Mixed Inka piece under study. (Photograph by the author); c) decorative patterns. (Drawings by F. Gili).

de un aríbalo cuzqueño (con un punto de quiebre en el tercio inferior del cuerpo, borde hiper-evertido y cuello hiperboloide). Un ejemplar similar se encuentra en el sitio Estadio Fiscal de Ovalle (pieza 205, en Cantarutti 2002), interpretado como una forma de inspiración cuzqueña que parece consolidarse en el extremo septentrional del Noroeste Argentino (fig. 3a). La decoración se presenta en campos trapezoidales dispuestos en el cuerpo, con un reticulado oblicuo fino y bajo el asa, y el motivo de líneas diagonales dobles perpendiculares (cruciforme) (fig. 3c). Se trata de un diseño altamente simétrico en el uso de colores y ejecución, que recuerda el tipo Cuzco Polícromo de Rowe (1944).

Los platos planos (fig. $4 \mathrm{a}$ y b) remitieron directamente a las formas definidas en la alfarería inka de las provincias (Matos 1999). Sin embargo, no se presentó la definición claramente ornitomorfa que se encuentra circulando en otros espacios (fig. 4b). La decoración del interior contiene motivos "populares" en Chile central y el Norte Chico. El primer plato plano (fig. 4a) posee una banda diametral y motivos opuestos en una configuración cuatripartita (fig. 4c). Considerando las unidades de los motivos, vemos que existen referentes Diaguita, en particular de la greca unida a un triángulo rectángulo (patrón zigzag, en González 1995). En tanto, el triángulo con línea segmentada parece ser una innovación del "motivo en arco" propio de los aríbalos y popular en el área central. El segundo plato plano presenta una banda diametral compuesta por reticulado fino-oblicuo y, en oposición a esta, trazos dentados terminados en volutas concéntricas. A estos últimos se les ha adjudicado un origen altiplánico-Saxamar (González 1995).

Para la categoría denominada "Alfarería de Fase Inka de referentes locales, Aconcagua y Diaguita", con- 


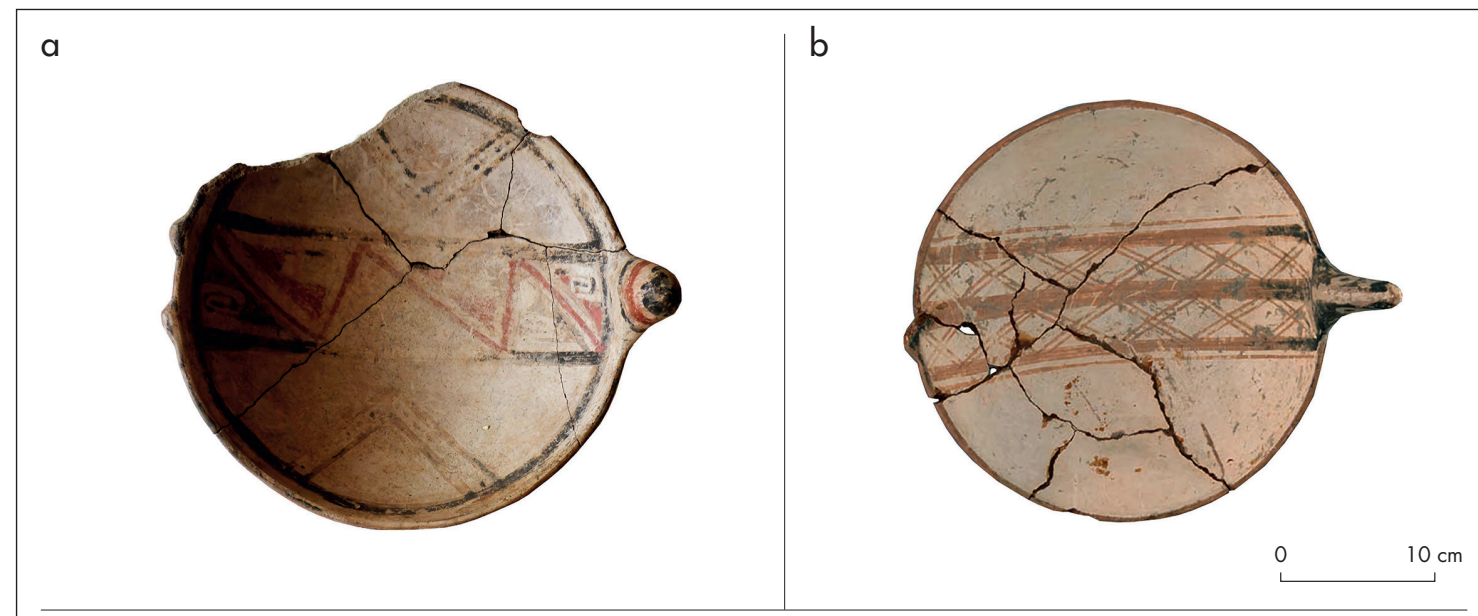

C
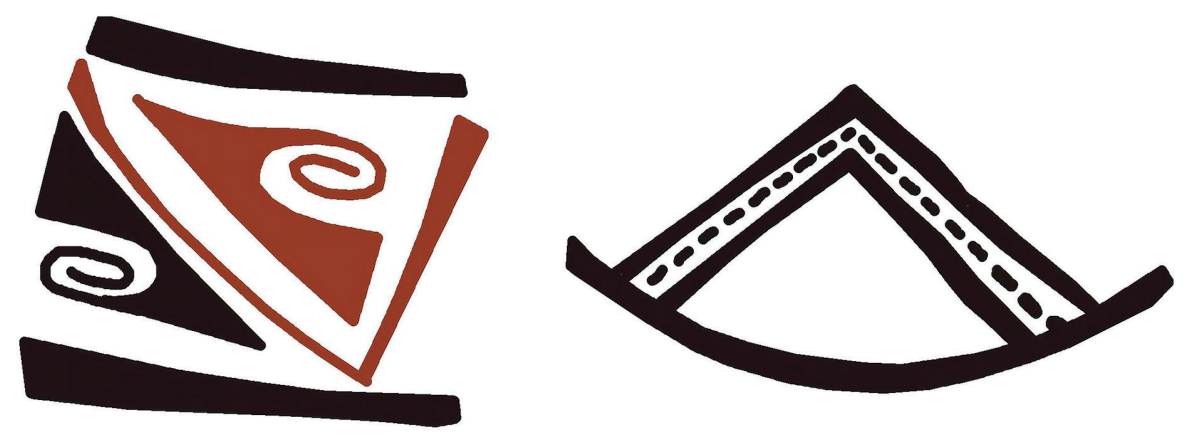

Figura 4. Plato plano con modelado ornitomorfo: a) ejemplar en estudio. (Fotografía de la autora); b) Limarí (modificado de Museo del Limarí 2018: ID1121); c) patrones decorativos. (Dibujos de F. Gili). Figure 4. Ornithomorph shaped flat plate: a) piece under study. (Photograph by the author); $\boldsymbol{b}$ ) Limarí (adapted from Museo del Limarí 2018: ID1121); c) decorative patterns. (Drawings by F. Gili).

sideramos que el grupo de ollas de morfología local se ubica en la porción media-inferior del Aconcagua (fig. 5a). Se trata de vasijas restringidas con cuello, de perfil inflectado y compuesto, cuello hiperboloide y cuerpo esférico a elipsoide. En esta forma se incorporaron rasgos decorativos diaguitas, en los que se respeta el uso de colores, una configuración bidireccional y una ejecución cuidada (fig. 5b). El diseño remite al motivo del "triángulo escalerado que termina en greca" (patrón cadenas, González 1995) con una direccionalidad zigzag oblicua a la izquierda. Las innovaciones respecto del patrón Diaguita, contemplaron cambios en la proporcionalidad de las unidades del motivo -la greca adquiere más tamaño- y en los usos de los campos en función de la morfología (cuello y cuerpo). En cuanto a las técnicas de manufactura, estas se separaron de las formas tradicionales, ya que los pigmentos no presentan problemas de cohesión y las huellas de uso se vinculan a prácticas de procesado, almacenado y tostado de contenidos que generaron alteraciones por sustracción.

En la categoría "Aconcagua Patrón Local de referentes locales y Aconcagua (Maipo Mapocho)", se registró el caso de ollas y escudillas cuyo modelo morfológico directo se encuentra en formas de hacer y tecnologías generales de la cultura Aconcagua (Massone 1978, Falabella 1997). Para las ollas es característica la escasa definición del perfil y el cuello corto que presentan (fig. 6a), como sus cuerpos ovoidales y asas verticales u oblicuas (fig. 6b). En algunas de estas se aprecia una decoración incisa en asas tipo "garra" (fig. 6c) y pastillaje, definido como "acordelado" (fig. 6d). Según Baudet (2004), se trataría de un rasgo presente solo en los sitios costeros de la zona. Entre las escudillas destacan ejemplares con un "motivo areal cruciforme", frecuentes para el Maipo 


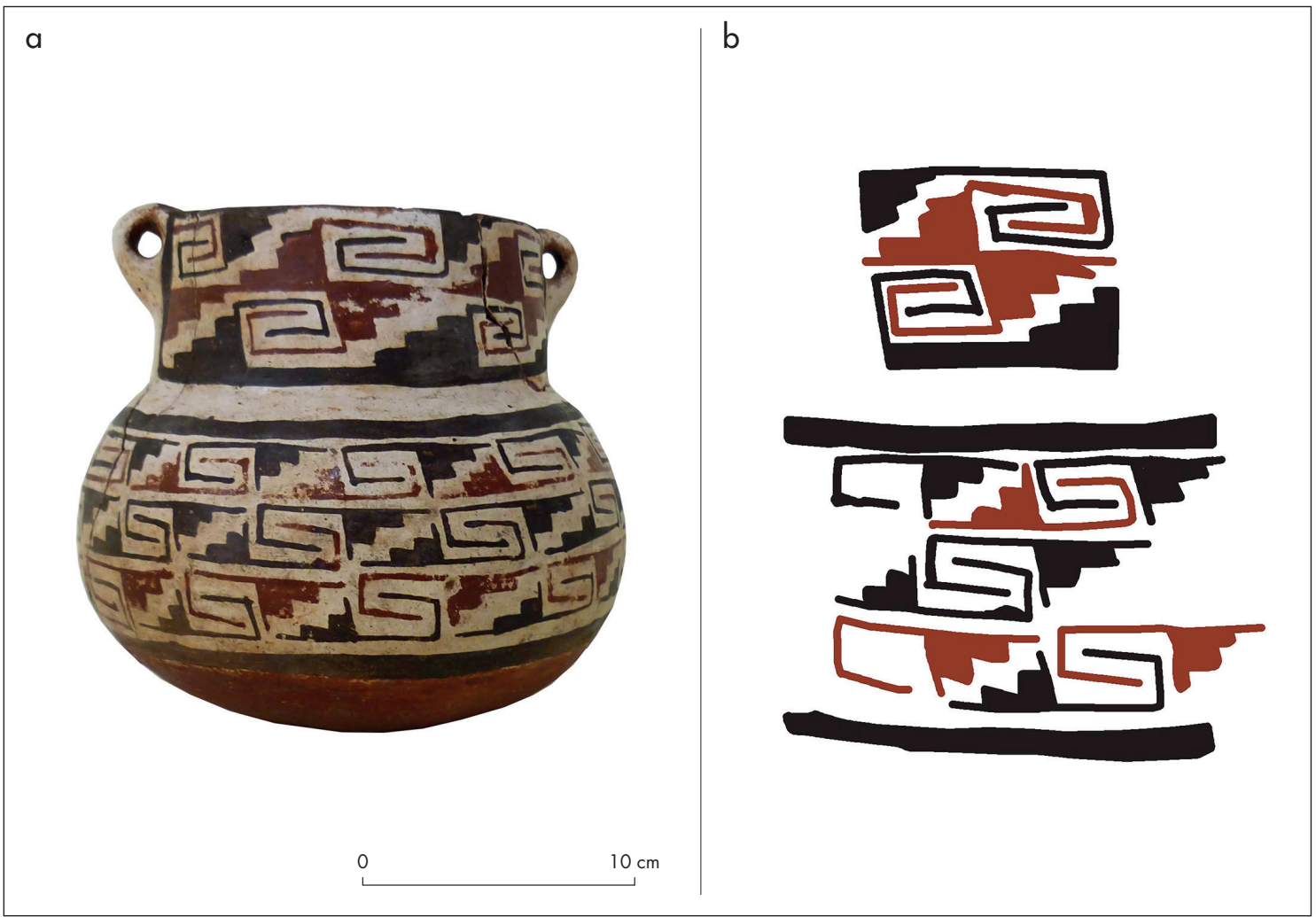

Figura 5. Olla: a) pieza en estudio. (Fotografía de la autora); b) patrones decorativos. (Dibujos de F. Gili). Figure 5. Pot: a) piece under study. (Photograph by the author); b) decorative patterns. (Drawings by F. Gili).

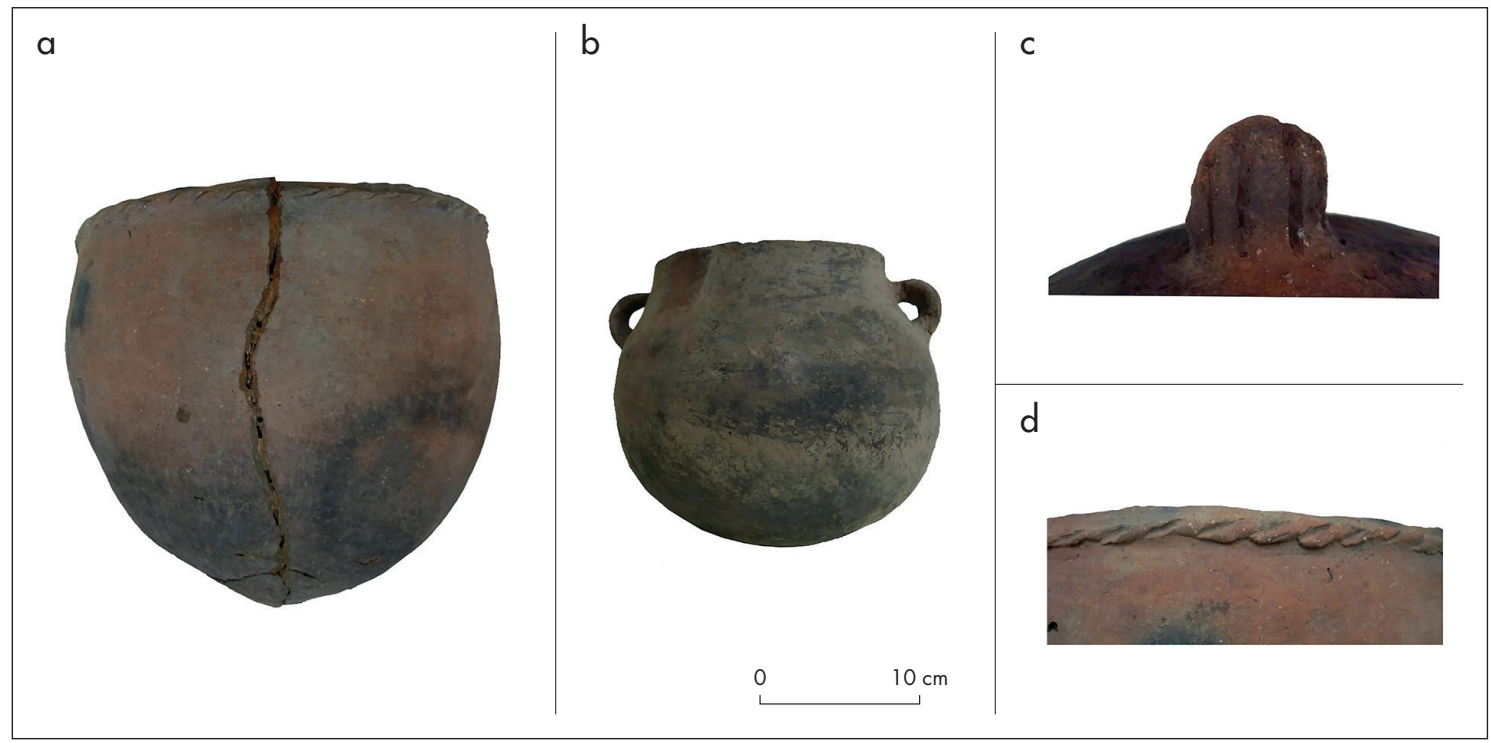

Figura 6. Ollas: a) sin asas; b) con asas; c) patrón decorativo asa "garra" inciso; d) patrón decorativo "acordelado" en borde. (Fotografías de la autora). Figure 6. Pots: a) without handles; $\boldsymbol{b}$ ) with handles; $\boldsymbol{c}$ ) incised "claw" decorative pattern; $d$ ) "rope like" decorative pattern on edge. (Photographs by the author). 


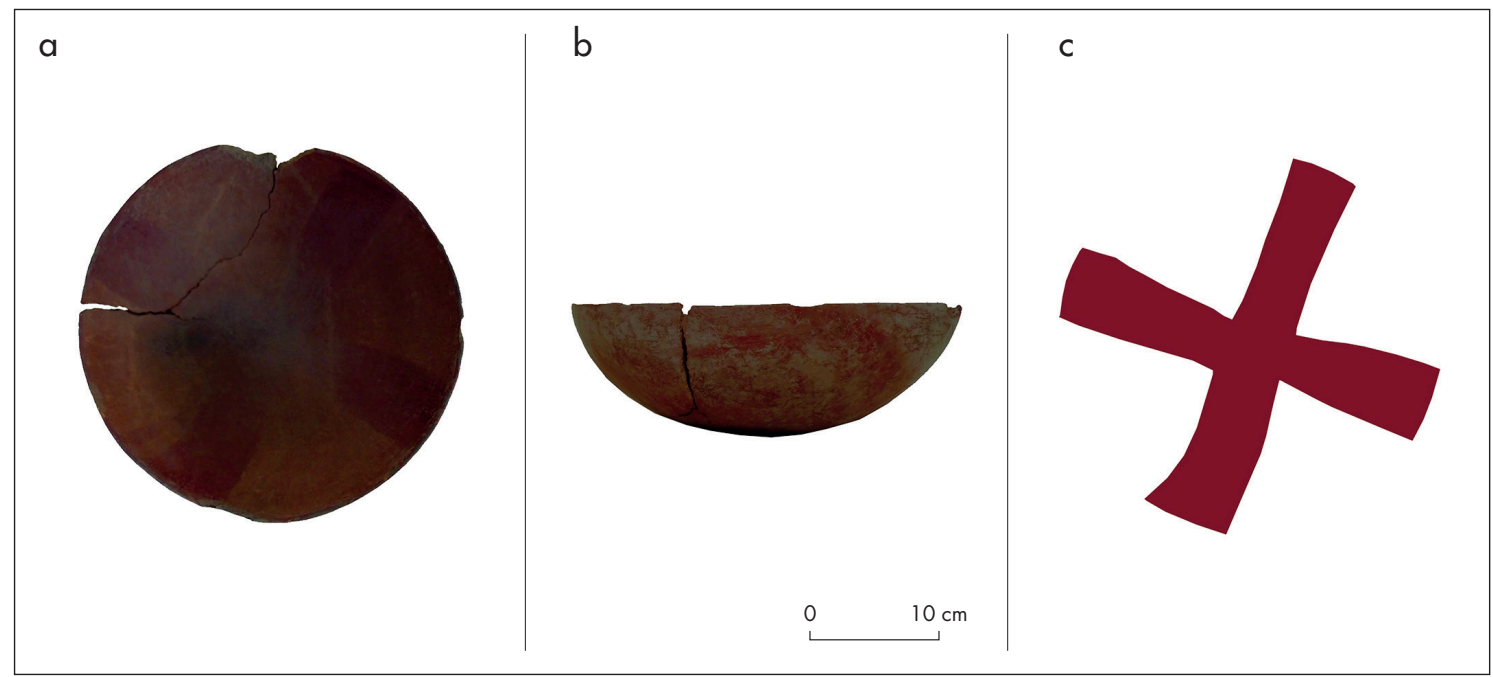

Figura 7. Escudillas en estudio: a) vista superior; b) vista frontal. (Fotografías de la autora); c) patrón decorativo cruciforme. (Dibujo de F. Gili). Figure 7. Bowls under study: $\boldsymbol{a}$ ) top view; $\boldsymbol{b}$ ) front view. (Photograph by the author); ) cruciform decorative pattern. (Drawing by F. Gili).

Mapocho y para el área de Pocuro (Dávila et al. 2018), donde resulta muy relevante la preferencia por la técnica del engobe en color rojo (fig. 7).

\section{ENSAYO DE UN ACONCAGUA "SIN NOSOTROS"}

Los análisis estilísticos de las piezas cerámicas atribuidas al contexto de expansión inka en Chile central, se entendieron tradicionalmente bajo la lógica de la dominación unilateral. Una idea fundada en la definición de un conjunto alfarero bastante estandarizado de formas y significados visuales, que delata la presencia e ideología estatal (Bray 2004). Sin embargo, esta cerámica evidenciaría distinciones a través del Tawantinsuyu, que no son solo morfológicas o decorativas, sino también de manufactura (composiciones químicas y petrográficas) (D’Altroy \& Bishop 1990). En algunos casos se ha establecido que la misma variabilidad observada en la alfarería inka de las regiones sería indicativa de la respuesta local a la incorporación estatal (Hayashida 1994).

Si bien, en el área no se registraron piezas de estilo Inka Cuzqueño, las vasijas "Inka Mixtas de referentes locales, cuzqueños y diaguitas" contrastan significativamente con aquellas que plasman solo atributos locales, por una elaboración cuidada en general, expresada tanto en la manufactura como en la ejecución de las decora- ciones. A su vez, la capacidad de tamaño y volumen de vasijas como los aríbalos permite plantear un uso para espacios de congregación social comunitaria y un mayor tiempo de almacenamiento. En tal sentido, se trató de un estilo particular que se apropió de diversos referentes, no solo cuzqueños, sino también procedentes del Noroeste Argentino y del Norte Chico, sin descartar la posibilidad de alusiones a espacios altiplánicos en contextos de producción alfarera que actuarían diferenciados de lo local (Fuenzalida 2014). Notoriamente, en este estilo no se incorporan diseños decorativos locales, situación que se diferencia de espacios como el Norte Chico.

Estas vasijas compartieron rasgos generales con los conjuntos registrados para la cuenca del Maipo Mapocho. La cercanía estilística puede ilustrarse con el caso de los aríbalos. En ellos parece existir, por un lado, un diseño morfofuncional, es decir, con base semiápoda o plana-cóncava, cuerpo de formas ovoidales y cónico-invertidas, con proporción del alto del cuello/ alto del cuerpo entre 70/30 y 80/20, y ausencia de otros caracteres propios del área nuclear. Por otro lado, se observa un diseño decorativo, con uso de planos situados en el cuerpo de las piezas, privilegio de la policromía y utilización de un amplio bagaje de referentes como Cuzqueño, Diaguita, Noroeste Argentino, entre otros, lo que podría relacionarse con elecciones y convenciones establecidas a nivel intercomunitario. Esto último también abre nuevas posibilidades para cotejar las 
destrezas y conocimientos que tuvieron que adquirir las comunidades alfareras en un nuevo contexto sociopolítico como el Tawantinsuyu que, sin descartar la presencia de mitimaes en la zona, fueron creando redes de trabajo, festividades y otros espacios de interacción entre valles, según sus posibilidades.

Un componente distintivo del curso medio-inferior del Aconcagua se expresó principalmente en referentes morfológicos como jarros y ollas con dos asas, de escasa apertura de la boca y un par de asas de orificios muy pequeños (para un uso posible de amarras). Estos aspectos plantean una funcionalidad relativa al transporte de líquidos de gran versatilidad. Para el caso de "Alfarería de Fase Inka de referentes locales, Aconcagua y Diaguita”, es relevante mencionar la incorporación en estas morfologías "locales" de los patrones decorativos Diaguita como signos que se pretenden exhibir. Se respetan estándares de composición generales y se percibe un cuidado en las ejecuciones, lo que permite postular la existencia de un mismo evento de producción y una mayor estandarización de los gestos alfareros. Ello sugiere la propia exigencia que el signo diaguita hace, interpelando al artesano y a la comunidad donde se inscribe.

En las piezas "Aconcagua Patrón Local" existió un vínculo claro con lo que se definió como cultura Aconcagua, lo que indicaría la perduración de la tradición alfarera local en un nuevo marco sociohistórico. Esto porque las fechas asignadas a esqueletos asociados a estas piezas revelan una continuidad en el tiempo hacia mediados de 1400 DC (Fuenzalida 2014). No obstante, esta perduración no puede ser leída estáticamente, ya que también conllevó transformaciones que operaron mayormente a nivel decorativo con preferencias por acabados, patrones de diseños, orientación y proporción de unidades de motivos, entre otras.

En consecuencia, las comunidades del Aconcagua se abrieron a la incorporación de nuevos estándares tecnológicos y pautas artísticas, asumiendo un rol activo cuando se recrearon motivos, se manipularon proporciones y composiciones según requerimientos intercomunitarios y comunitarios, como también por las "exigencias" que la misma materialidad y signo político implicaban. Desde la confluencia de referentes, es posible apoyar la existencia de una tradición alfarera andina de expresión meridional. Esta tradición tiene un origen preinkaico en el que circularon estilos morfológicos, decorativos y tecnológicos Diaguita, Aconcagua y otras manifestaciones locales como la analizada, las que se incluyeron más tarde en el sistema de códigos gráficos para tiempos de dominación inka y, en algunas zonas, se perpetuaron hacia el primer siglo colonial (PrietoOlavarría \& Tobar 2017).

\section{CONCLUSIONES}

En este trabajo problematizamos la noción de estilo en el marco del debate de la colonialidad del poder-saber y sus implicancias. Las perspectivas tradicionales utilizaron mecanismos de explicación social fundados en una actuación pasiva, tanto de la materialidad como de las identidades en juego. Fuera de los matices, la escasa reflexión respecto del traslado de énfasis civilizatorios implícitos hacia realidades pasadas conduce a invisibilizar y reproducir hegemonías con efectos colonialistas de larga data, entre arqueologías y proyectos nacionales (Gnecco 2002, Endere \& Ayala 2012). Luego, si bien se admite la condición colonialista de la arqueología en sus orígenes, no se cuestiona la práctica, la escritura y el saber que esta matriz alberga.

Así, el gran desafío es ensayar una "superación" de la huella colonial por medio del uso de conceptos imprescindibles como el de estilo. Este trabajo es un punto de partida, que puede aportar en la problematización de los "espacios fronterizos" del Tawantinsuyu, con acento en las agencias locales, especialmente con relación a la que se plantea como una materialidad muy relevante durante el Período Tardío y muy importante para el curso medio-inferior del Aconcagua, no solo por sus cualidades intrínsecas (como durabilidad o ubicuidad), sino también porque se carece de otros medios de expresión, como el arte rupestre. Junto a ello, se debe ponderar la inversión significativa que implicó la instalación de estos bienes en el ámbito mortuorio, la que debió considerar la selección de ciertos atributos estilísticos en otras dimensiones. Esta porción del Aconcagua no solo adquirió una importancia estratégica en términos geográficos y políticos en tiempos de expansión inka, sino también en su conformación como un espacio de congregación comunitario y ritual fúnebre a nivel de valle.

El predominio de la tradición local alfarera en contextos mortuorios se uniría a otras esferas que caracterizaron el modo de vida de las comunidades, como el patrón habitacional o tradiciones tecnológicas como la lítica, que parecen persistir sin albergar trasformaciones fundamentales durante este período (Pascual 
2012, Pavlovic et al. 2019). Ello refuerza la idea de que la articulación del Inka con lo local se desarrolló bajo principios de inclusión y exclusión (Sánchez 2004), como parte importante de la práctica política estatal, pero también en relación con los esfuerzos comunitarios por diferenciarse, persistir, resistir y resignificar el nuevo orden. Asimismo, nuevas nociones de dominio apuntan a entender la interacción desde el despliegue festivo, patrocinado por el Tawantinsuyu (Pavlovic et al. 2019). Por ello, el proceso de expansión inka no puede entenderse a cabalidad con base en el pensamiento dicotómico y civilizatorio "sobre lo local", sino como resultado de estrategias, oportunidades, negociaciones o conflictos propios del encuentro entre múltiples agencias y relaciones.

Independientemente de la interpretación del espacio sociogeográfico, quisimos enfatizar una comprensión del estilo alfarero como producto cultural, relativo a procesos continuos de creación, selección y elecciones. Dichos procesos se hicieron en función de cercanías sociales y políticas o del sello artístico que implica a su vez gustos, habilidades, entre otros, así como de los constreñimientos contextuales y mecanismos de recepción. Un camino a seguir consiste en poner en diálogo esta propuesta con otros soportes y contextos. Se perciben aplicaciones interesantes para los complejos arquitectónicos reconocidos en Chile central, ubicados en cumbres de cerros isla y colinas. Estos, a diferencia de lo acontecido a nivel alfarero, no tienen antecedentes de desarrollo preinkaico y por mucho tiempo se asumieron como instancias homogéneas. Se puede relevar, preliminarmente, el encuentro de referentes de estilo Inka en patrones constructivos y técnicos del trabajo en piedra, en el dominio visual sobre los valles y relación con wakas cordilleranas, principios de simetría, etc.; y también locales, con adaptaciones a pendientes e innovaciones en formas circulares, entre otros (Pavlovic et al. 2019, Troncoso et al. 2012).

Las ideas anteriormente expuestas reflejan los "lentes" que, usados hoy, nos obligan a reducir el pasado caleidoscópico y prehistórico. Para finalizar, se plantea que el arqueólogo(a), en la experiencia de la investigación, no puede dejar de inquietarse por el pasado disciplinar y no considerarse como "heredero(a) responsable" (sensu Derrida 2019) inscrito en una genealogía. Nos sumamos a la demanda que se hace desde la inflexión descolonizadora por el desarrollo de nuevas prácticas que superen complejos civilizatorios, paternalismos y supremacías retóricas. Pensamos, sin superar aún la huella colonial, que podemos, al menos, concientizar sobre las implicancias del uso de nuestros lentes y avanzar así hacia nuevos horizontes de análisis.

Agradecimientos Quisiera agradecer a Daniel Pavlovic, FonDECYT 1090680, y al equipo cerámico. A Lorena Sanhueza. A la directora del Museo Histórico y Arqueológico de Quillota, Pamela Maturana y profesionales. A Francisca Gili.

\section{NOTAS}

${ }^{1}$ Este trabajo corresponde a una reflexión de la tesis de grado de la autora (Fuenzalida 2014), en la cual se detallan diversos aspectos de orden teórico, metodológico y contextual.

${ }^{2}$ Los estudios culturales latinoamericanos podrían definirse como un campo de saber configurado a partir de la tradición crítica latinoamericana, en diálogo con escuelas de pensamiento norteamericanas y europeas, que problematiza la modernidad, la identidad y la cultura latinoamericana en la literatura, el arte en general y la cultura material, entre otros (Ríos 2002).

${ }^{3}$ Espacio geográfico ubicado entre la localidad de Hijuelas, donde el río se curva al sur, hasta las comunas de La Calera y Nogales, alcanzando mayor amplitud hacia su tramo inferior, correspondiente a la comuna de Quillota (Fuenzalida 2014).

${ }^{4}$ La representación de las decoraciones alfareras Diaguita para la zona cultural del Norte Chico realizada por González (1995) se transformó con los años en un ícono inspirador del arte.

${ }^{5}$ Dados los objetivos de esta exposición, no se tematiza la procedencia específica de estos bienes. Los contextos de uso y consumo refieren a las fiestas funerarias (Morris 1995), entendidas como escenarios socioeconómicos particulares del período (Fuenzalida 2014: 26).

${ }^{6}$ Se trabajó con las colecciones del Museo Histórico y Arqueológico de Quillota y del Museo Histórico de La Cruz, integradas por diversos hallazgos y grandes sitios arqueológicos funerarios (entre ellos, Estadio Quillota, Carolina, Maltería, Fundo Esmeralda), que comprenden un total de 173 vasijas, unas restauradas y otras no, cuyo grado de completitud fue mayor al 40\%. Para evaluar el diseño morfológico se registró la forma general de cada vasija según Shepard (1956). La decoración se abordó con la identificación de la aplicación del color y las técnicas plásticas, la configuración de los colores y motivos, la valoración cualitativa y cuantitativa de la prolijidad, y la ejecución de los mismos (gama de colores, trazos netos o impuros, ancho de las pinceladas). Además, se evaluaron rangos de tamaños, volúmenes, huellas de uso y manufactura, entre otros (Fuenzalida 2014). 


\section{REFERENCIAS}

Adorno, R. 1984. Paradigmas perdidos: Guamán Poma examina la sociedad española colonial. Chungara 13: 67-91.

AdoRno, R. 1988. Nuevas perspectivas en los estudios literarios coloniales hispanoamericanos. Revista Crítica Literaria Latinoamericana XIV (28): 11-28 .

Ambrosetti, J. 1907. Exploraciones arqueológicas en la ciudad prehistórica de La Paya (valle Calchaquí, Provincia de Salta): campañas de 1906 y 1907. Vol. II. Buenos Aires: Universidad de Buenos Aires-Real Academia Hispano Americana de Ciencias, Artes y Letras.

Ansaldi, W. \& Giordano, V. 2012. América Latina. La construcción del orden. De la Colonia a la disolución de la dominación oligárquica. Vol. I. Buenos Aires: Ariel.

Ávalos, H. \& Saunier, A. 2011. Primera parte: Arqueología. In Arqueología e historia del curso medio e inferior del río Aconcagua. Desde los primeros alfareros hasta el arribo de los españoles (300 AC-1600 DC), F. Venegas, ed., pp. 19-130. Valparaíso: Ediciones Universitarias.

Barros Arana, D. 2000 [1884]. Historia general de Chile. Vol. I. Santiago: Centro de Investigaciones Diego Barros Arana-Editorial Universitaria.

Baudet, D. 2004. Una revalorización del tipo Aconcagua Pardo Alisado. Chungara 36 (2): 711-722.

Boccara, G. 1999. Antropología diacrónica. Dinámicas culturales, procesos históricos y poder político. In Lógica mestiza en América, G. Boccara \& S. Galindo, eds., pp. 2160. Temuco: Instituto de Estudios Indígenas, Universidad de La Frontera.

Bourdieu, P. 2012. Homo academicus. Buenos Aires: Siglo XXI.

BRAY, T. 2004. La alfarería imperial inka: una comparación entre la cerámica estatal del área del Cuzco y la cerámica de las provincias. Chungara 36 (2): 365-374.

BRENDECKE, A. 2012. Introducción. In Imperio e información. Funciones del saber en el dominio colonial español, A. Brendecke, ed., pp. 15-42. Madrid-Frankfurt: Iberoamericana-Vervuert.

Calderari, M. \& Williams, V. 1991. Reevaluación de los estilos cerámicos incaicos en el Noroeste Argentino. El imperio inka, actualización y perspectivas por registros arqueológicos y etnohistóricos. Comechingonia 9: 73-95.

Cantarutti, G. 2002. Estadio Fiscal de Ovalle: redescubrimiento de un sitio diaguita-inca en el valle del Limarí (Región de Coquimbo, Chile). Undergraduate thesis in Anthropology, Departamento de Antropología, Universidad de Chile. <http://repositorio.uchile.cl/handle/2250/135382> [consultado: 05-04-2021].

Cantarutti, G. \& Mera, R. 2002. Alfarería del cementerio Estación Matucana: ensayo de clasificación y relaciones con la cerámica del Período Inca de Chile Central y áreas vecinas. Werkén 3: 147-170.

CARR, C. \& NeITzeL, J. 1995. Style, society and person: archaeological and ethnological perspectives. New York: Plenum Press.
Colmenares, G. 2006. Las convenciones contra la cultura. Ensayos sobre la historiografía hispanoamericana del siglo XIX. Santiago: DIBAM.

Contreras, H. 2004. Servicio personal y comunidades indígenas en el valle de Quillota durante los primeros años del asentamiento español, 1554-1569. Cuadernos Interculturales 2 (3): 69-84.

Contreras, H. 2010. Los conquistadores y la construcción de la imagen del indio en Chile Central. In América colonial. Denominaciones, clasificaciones e identidades, A. Araya \& J. Valenzuela, eds., pp. 49-79. Santiago: RIL Editores.

Correa, I., Bahamondes, F. \& Solervicens, C. 2007-2008. Contextos alfareros de interacción social: lo local y lo foráneo en el cementerio inca de Quinta Normal. Revista Chilena de Antropología 19: 143-171.

Cornejo Polar, A. 1997. Mestizaje e hibridez: los riesgos de las metáforas. Apuntes. Revista Iberoamericana LXIII (180): 341-344.

Cummins, T. 2004. Brindis con el Inca. La abstracción andina de las imágenes coloniales de los queros. Lima: Fondo Editorial de la Universidad Nacional Mayor de San Marcos-Universidad Mayor de San Andrés-Embajada de los Estados Unidos de América.

D’Altroy, T. \& Bishop, R. 1990. The provincial organization of inka ceramic production. American Antiquity 55: $120-138$.

Dávila, C., Cortés, C., Martínez, A., Hermosilla, J., Fuenzalida, N. \& Pavlovic, D. 2018. Interacción social al sur del Collasuyu. Alfarería funeraria del Período Tardío (1400-1536 DC) en la cuenca del Maipo-Mapocho. Chungara 50 (4): 577-590.

DERRIDA, J. 2019. Esa extraña institución llamada literatura. In Escenas de escritura. Entre filosofía y literatura, C. Olivares, ed., pp. 69-126. Santiago: Pólvora Editorial.

Dietler, M. \& Herbich, I. 1998. Habitus, techniques, style: an integrated approach to the social understanding of material culture and boundaries. In The archaeology of social boundaries, M. Stark, ed., pp. 232-263. Washington DC: Smithsonian Institution Press.

Domingo, I. \& Fiore, D. 2014. Style: its role in the archaeology of art. In Encyclopedia of Global Archaeology, C. Smith, ed., pp. 7104-7111. New York: Springer.

Dussel, E. 2004. Sistema mundo y transmodernidad. In Modernidades coloniales, S. Dube, I. Banerjee \& W. Mignolo, eds., pp. 201-226. Mexico City: El Colegio de México.

Echeverría, B. 2011. La modernidad de lo barroco. Mexico City: Ediciones Era.

Endere, M. L. \& Ayala, P. 2012. Normativa legal, recaudos éticos y práctica arqueológica. Un estudio comparativo de Argentina y Chile. Chungara 44 (1): 39-57.

Falabella, F. 1997. El estudio de la cerámica Aconcagua en Chile Central: una evaluación metodológica. In Actas del XIV Congreso Nacional de Arqueología Chilena, vol. I, pp. 427-458. Copiapó: Sociedad Chilena de Arqueología. 
Fernández BACA, J. 1971. Motivos de la ornamentación de la cerámica Inca Cuzco. Lima: Librería Studium.

FrIEDRICH, M. H. 1970. Design structure and social interaction: archaeological implications of an etnographic analysis. American Antiquity 35 (3): 332-343.

Fuenzalida, N. 2014. La vida en la muerte: resistencias e incanización en la alfarería fúnebre de las comunidades del curso medio-inferior del Aconcagua. Undergraduate thesis in Anthropology, Departamento de Antropología, Universidad de Chile.

Gajardo, R. \& Silva, J. 1970. Notas sobre la arqueología de Quillota. San Felipe: Editorial Jerónimo de Vivar.

Gallardo, F., Cabello, G., Pimentel, G., Sepúlveda, M., \& Cornejo, L. 2012. Flujos de información visual, interacción social y pinturas rupestres en el desierto de Atacama (norte de Chile). Estudios Atacameños 43: 35-52.

GeLl, A. 1994. The technology of enchantment and the enchantment of technology. In Anthropology, Art, and Aesthetics, J. Coote \& A. Shelton, eds., pp. 40-63. Oxford: Clarendon Press.

Gnecco, C. 2002. La indigenización de las arqueologías nacionales. Convergencia 9 (27): 133-149.

Gnecco, C. \& Langebaek, C. H. 2006. Contra la tiranía del pensamiento tipológico. In Contra la tiranía en arqueología: una visión desde Sudamérica, C. Gnecco \& C. H. Langebaek, pp. IX-XIv. Bogota: Uniandes.

González, C. 200o. Comentarios arqueológicos sobre la problemática inca en Chile Central (primera parte). Boletín de la Sociedad Chilena de Arqueología 29: 39-50.

GonZÁLEZ, P. 1995. Diseños cerámicos Diaguita-Inka: estructura, simbolismo, color y relaciones culturales. Undergraduate thesis in Anthropology, Departamento de Antropología, Universidad de Chile.

GonzÁlez, P. 2013. Arte y cultura diaguita chilena: simetría, simbolismo e identidad. Santiago: Ucayali Editores.

Gosselain, O. 2000. Materializing identities: an african perspective. Journal of Archaeological Method and Theory 7 (3): 187-217.

GruZInski, S. 1994. La guerra de las imágenes. De Cristóbal Colón a "Blade Runner" (1492-2019). Mexico City: Fondo de Cultura Económica.

GRUZINSKI, S. 1991. La colonización de lo imaginario. Sociedades indígenas y occidentalización en el México español. Siglos XVI-XVIII . Mexico City: Fondo de Cultura Económica.

HABER, A. 2011. Nometodología payanesa: notas de metodología indisciplinada. Revista Chilena de Antropología 23: 9-49.

Hayashida, F. 1994. Producción cerámica en el imperio inca: una visión global y nuevos datos. In Tecnología y organización de la producción cerámica prehispana en los Andes. I. Shimada, ed., vol. I, pp. 443-475. Lima: Pontificia Universidad Católica del Perú.

Hegmon, M. \& Kulow, S. 2005. Painting as agency, style as structure: innovations in mimbres pottery designs from southwest New Mexico. Journal of Archaeological Method and Theory 12 (4): 313-334.
HodDer, I. 1982. Symbols in action: etnoarchaeological studies of material culture. New York: Cambridge University Press.

Ingold, T. 2012. Toward an ecology of materials. Anual Review of Anthropology 41 (1): 427-442.

Kopythoff, I. 1991. La biografía cultural de las cosas: la mercantilización como proceso. In La vida social de las cosas, A. Appadurai, ed., pp. 89-122. Mexico City: Grijalbo.

Lechtman, H. 1977. Style in technology: some early thoughts. In Material culture: styles, organization and dynamics of technology, H. Lechtman \& R. S. Merrill, eds., pp. 3-20. Saint Paul: West Publishing Company.

LETELIER, J. 2017. Arquitectura y espacio. Estrategias de dominio incaico en el valle del Aconcagua, Región de Valparaíso, Chile. Materialidades 5: 31-52.

Lugones, M. 2011. Hacia un feminismo descolonial. La manzana de la discordia 6 (2): 105-119.

Martínez, J. L., Díaz, C., Tocornal, C. \& Arévalo, V. 2014. Comparando las crónicas y los textos visuales andinos. Elementos para un análisis. Chungara 46 (1): 91-113.

Massone, M. 1978. Los tipos cerámicos del complejo cultural Aconcagua. Undergraduate thesis in Anthropology, Departamento de Antropología, Universidad de Chile.

Matos, R. 1999. La cerámica inca. In Los incas. Arte y simbolismo, C. Morris, F. Pease \& J. Santillana, eds., pp. 109-165. Lima: Banco de Crédito del Perú.

Meyers, A. 1975. Algunos problemas en la clasificación del estilo Incaico. Pumapunku 8: 7-25.

Morris, I. 1995. Symbols to power. Styles and media in the Inka State. In Style, society and person, archaeological and ethnological perspectives, C. Carr \& J. E. Nietzel, eds., pp. 419-433. New York: Plenum Press.

Nitschack, H. 2016. "Mestizagem" y "transculturación" como políticas y prácticas de convivencia: Gilberto Freyre (CasaGrande y Senzala, 1933) y Fernando Ortiz (Contrapunteo cubano del tabaco y del azúcar, 1940). Ístmica 19: 15-35.

Olsen, B. 2007. Genealogías de la asimetría: por qué nos hemos olvidado de las cosas. Complutum 18: 283-319.

OyArzún, A. 1910. Contribución al estudio de la influencia de la civilización peruana sobre los aborijenes de Chile. Boletín del Museo Nacional de Historia Natural de Chile 2: 3-37.

PÁez, M. C. \& Giovannetti, M. 2008. Intersecciones y síntesis, sincretismos en los platos del período incaico en el Noroeste Argentino. Arqueología Suramericana 4 (2): 169-190.

Pascual, D. 2012. Función de sitios en el Período Tardío en el curso medio y superior del valle del río Aconcagua. Una discusión sobre la base de la organización tecnológica del material lítico. Undergraduate thesis in Anthropology, Departamento de Antropología, Universidad de Chile.

Pavlovic, D., Troncoso, A., SÁnchez, R. \& Pascual, D. 2012. Un tigre en el valle. Vialidad, arquitectura y ritualidad incaica en la cuenca superior del río Aconcagua. Chungara 44 (4): 551-569.

Pavlovic, D., Sánchez, R., Pascual, D., Martínez, A., Cortés, C., Dávila, C. \& La Mura, N. 2019. Rituales 
de la vida y de la muerte: dinámicas de interacción entre el Tawantinsuyu y las poblaciones locales en la cuenca del Maipo-Mapocho, Chile central. Estudios Atacameños 63: 43-80.

Prieto-Olavarría, C. \& Tobar, V. 2017. Interacciones y lenguajes visuales en la cerámica local de los períodos Inca y Colonial (centro oeste argentino). Estudios Atacameños 55: 135-161.

QuiJano, A. 1999. Colonialidad del poder, cultura y conocimiento en América Latina. Dispositio. Crítica cultural en Latinamérica: paradigmas globales y enunciaciones locales 24 (51): 137-148.

RAPPAPORT, J. 2015. Letramiento y mestizaje en el nuevo reino de Granada, siglos XVI y XVII. Diálogo Andino 46: 9-26.

Rowe, J. 1944. An introduction to the archaeology of Cuzco. Papers of the Peabody Museum of American Archaeology and Ethonology xxviI (2): 3-69.

Ríos, A. 2002. Los estudios culturales y el estudio de la cultura en América Latina. In Estudios y otras prácticas intelectuales latinoamericanas en cultura y poder, D. Mato, coord., pp. 247-254. Caracas: CLACSO y CEAP-FACES-Universidad Central de Venezuela.

Rodríguez, M. G., Morales, R., González, C. \& JaCkson, D. 1993. Cerro La Cruz: un enclave económico-administrativo incaico, curso medio del río Aconcagua. In Actas del XII Congreso Nacional de Arqueología Chilena, vol. 2, pp. 201222. Temuco: Sociedad Chilena de Arqueología.

SACKeT, J. R. 1990. Style and ethnicity in archaeology: the case for isochrestism. In The uses of style in archaeology, M. Conkey \& C. A. Harstof, eds., vol. 1, pp. 32-43. Cambridge: University Press.

SÁnchez, R. 2001-2002. El Tawantinsuyu salvaje en el Finis Terrae Australis (Chile central). Revista Chilena de Antropología 16: 87-127.

SÁnchez, R. 2004. El Tawantinsuyu en Aconcagua (Chile central). Chungara 36 (2): 325-336.

Sánchez, R., Pavlovic, D., González, P. \& Troncoso, A. 2004. Curso superior del río Aconcagua: un área de interdigitación cultural. Períodos Intermedio Tardío y Tardío. Chungara 36 (2): 753-766.

Sanhueza, L. 2001. El aríbalo inka en Chile central. Werkén 2: 47-69.

SAnhuezA, L. 2004. Estilos tecnológicos e identidades sociales durante el Período Alfarero Temprano en Chile central. Una mirada desde la alfarería. Undergradutae thesis in Anthropology, Departamento de Antropología, Universidad de Chile.

SALOMON, F. 2001. Una etnohistoria poco étnica. Nociones de lo autóctono en una comunidad peruana. Desacatos 7: 65-84.

Shanks, M. \& Tilley, C. 1992. Style and ideology. In Reconstructing archaeology. Theory and practice, M. Shanks \& C. Tilley, eds., pp. 137-171. Cambridge: University Press. SHEPARD, A. 1956. Ceramics for the archaeologist. Washington: Carnegie Institution of Washington.
Silva, O. 1978. Consideraciones acerca del Período Inca en la cuenca de Santiago. Boletín del Museo Arqueológico de La Serena 16: 211-243.

STARK, M. 1999. Social dimensions of technical choice in Kalinga ceramic traditions. In Material meanings: critical approaches to the interpretation of material culture, E. S. Chilton, ed., pp. 24-43. Salt Lake City: University of Utah Press.

Stehberg, R. \& Sotomayor, G. 2012. Mapocho incaico. Boletín del Museo Nacional de Historia Natural 61: 85-149.

STOLCKE, V. 2007. Los mestizos no nacen, se hacen. In Identidades ambivalentes en América Latina (siglos XVI-XXI), V. Stolcke \& A. Coello, eds., pp. 14-51. Barcelona: Bellaterra.

Troncoso, A., Pavlovic, D., Acuto, F., Sánchez, R. \& González García, A. 2012. Complejo arquitectónico cerro Mercachas: arquitectura y ritualidad incaica en Chile central. Revista Española de Antropología Americana 42 (2): 293-319.

Uribe, M. 1999-2000. La arqueología inka en Chile. Revista Chilena de Antropología 15: 63-97.

VAlenzuela, J. 2010. Inmigrantes en busca de identidad. Los indios cuzcos de Santiago de Chile, entre clasificación colonial y estrategia social. In América colonial. Denominaciones, clasificaciones e identidades, A. Araya \& J. Valenzuela, eds., pp. 81-118. Santiago: RIL.

Verdesio, G. 2012. Colonialismo acá y allá: reflexiones sobre la teoría y práctica de los estudios coloniales a través de fronteras culturales. Cuadernos del CILHA 13 (17): 175-191.

Viveiros de CAStro, E. 2017. A inconstância da alma selvagem e outros ensaios de antropologia. São Paulo: Ubu Editora.

Wiessner, P. 1990. Is there a unity of style? In The uses of style in archaeology, M. Conkey \& C. Harstof, eds., pp. 105-112. Cambridge: University Press.

Wовsт, M. H. 1977. Stylistic behavior and information exchange. In For the Director: research essays in honour of James R. Griffin, C. E. Cleland, ed., pp. 317-342. Ann Arbor: Museum of Anthropology, University of Michigan. 